\title{
THE TOURINHO MODEL: \\ NEGLECTED NUGGET OR A RECEDING RELIC
}

\section{Roger Adkins*}

University of Salford, UK

Dean Paxson**

University of Manchester, UK

JEL Classifications: D81, G31

Keywords: Oil shale extraction, option holding cost, stochastic investment cost

* SBS, University of Salford, Greater Manchester, M5 4WT, UK. r.adkins@salford.ac.uk, +44 (0)1612953206. Corresponding author.

** Manchester Business School, Manchester, M15 6PB, UK. 


\title{
THE TOURINHO MODEL: NEGLECTED NUGGET OR A RECEDING RELIC
}

\begin{abstract}
As one of the earlier contributors to the body of real options literature, the Tourinho model on oil shale extraction is assessed for its legacy. His risk neutral investment deferral model elicits an extraction paradox of infinite deferral and no extraction. Although this is remedied by introducing an option holding cost or a time dependent rising investment cost, it is established that the source of the difficulty is due to the absence of a convenience yield. We demonstrate that by including a convenience yield in the holding cost deferral investment model, the resulting solution lies somewhere between the Marshallian zero volatility solution and the standard real option investment deferral solution. Option holding costs are infrequently adopted in real option models, but they represent a continuous cost of keeping an option alive and are characterised by land taxes prior to real estate development, rents prior to resource extraction and ongoing costs to sustain a technological edge before market release. Their consequence is to accelerate the value level triggering investment. Similar results are obtained for a stochastic investment cost.
\end{abstract}

\section{Introduction}

Sometimes, the origins of a theory are not sufficiently distinct or clear-cut to enable a common agreement to coalesce around a single seminal contribution that spawned the development of the subject as we know it today. Real options analysis has its roots in financial option theory whose history is well known and undisputed, but there is less certainty concerning the identity of the original influential use of option theory to real investment opportunities that spawned the rich theoretical developments and the multitude of applications in such diverse fields as exploration, construction, technology and competition. The aims of this essay are to critically appraise one of the earliest contributions, the thesis of Tourinho (1979), as a pioneering contribution in the field of real options theory and application, and to assess its position in shaping later developments of the subject. We explore the extent that his continuous time risk neutral deferral investment model is seminal in comparison to later notable contributions in a similar vein, such as McDonald \& Siegel (1986) and Brennan \& Schwartz (1985).

The subject of his thesis is the identification of the conditions conducive to the extraction of oil from shale when the oil price is the only source of uncertainty. Previous contributions to this research area focus on determining the conditions prompting resource extraction under various forms of uncertainty but outside of an options 
framework. The outstanding merit of the options approach lies in treating the asset prior to extraction as an option and using a risk neutral valuation procedure to correctly value the asset worth in the presence of asymmetric payoffs, Myers \& Turnball (1976). To set the landscape for his analysis, Tourinho first establishes that under either certainty or uncertainty, the resource is never extracted. This is referred to as the extraction paradox. However, since we observe option holders extracting their resource at a definite time, there has to exist suitable incentives, such as an option holding cost prior to extraction or a rising extraction cost, which induce the holders to exercise the option. He then proceeds to investigate these two distinct inducements separately within a framework of real options analysis.

Our discussion starts with the extraction paradox. We demonstrate using standard real options analysis that under his formulation, the resource is never extracted. However, Tourinho ignores the presence of the convenience yield for the extracted resource. We show that its absence is the cause of the paradox's existence and when the convenience yield is included in the formulation, the extraction paradox disappears. The extraction paradox is fundamental to his analysis since it motivates the introduction of inducements that will force the prospective resource extractor to exercise the option within a finite time period. The first inducement to be considered by Tourinho is the option holding cost, which is a cost such as an opportunity cost of the land containing the resource or a tax levied on not exercising the option. He demonstrates that the introduction of the holding cost into the formulation produces a feasible solution and claims that resource extractors exercise the investment opportunity within a finite time period because of the levies imposed on keeping the option open. Although the solution is feasible, two issues complicate his findings. First, the exercise price is specified as the accumulation of the investment cost apportioned over the entire resource quantity and the unit operating cost. Joining the apportioned investment cost with the continuous operating costs with their different functions and timings does create ambiguities when considering the effect of unfavourable resource price changes on the operating policy and suspension possibilities, although these are not a focus of his model. Second, the solution is not feasible for all possible values of the holding cost although Tourinho would claim that a minimal 
holding cost is required to overcome the extraction paradox. On this point, we investigate the model involving the convenience yield as well as the holding cost. The analysis reveals that the solution is feasible for all possible values of the holding cost. Further, the option holding cost exerts a greater influence on the solution than the convenience yield. More significantly, we show that the option holding cost acts as a mediator of the optimal exercise policy between the Marshallian condition and the standard real options investment opportunity condition and that increase in the option holding cost reduce the mark-up level required to exercise the option. The option holding cost therefore shares with competition the capacity to moderate the required mark-up towards the Marshallian level.

We provide a brief description of the model involving a storage cost teaming up with an option holding cost. His model is not so tractable analytically and his numerical results derived from a finite difference procedure show that the introduction of the storage cost has only a slight effect on his previous findings.

The alternative inducement for overcoming the extraction paradox is to make the exercise price to increase exponentially over time. Tourinho relies on a ploy to obtain his result. Since the option function has to have a high impact merger with the net value from exercising the option, one of the generic solutions to the partial differential equations is eliminated. However, reformulating the model to include the convenience yield avoids this ploy and therefore his findings are not absolutely secure. It is possible to introduce both the option holding cost and the changing exercise price into the formulation having a positive convenience yield. This reveals, significantly, that the mark-up factor required for exercising the option adopts a form similar to the standard real options investment opportunity result and that the inclusion of a positive holding cost produces a mark-up value which is always less than that prescribed by the standard result.

Our discussion of the Tourinho paper is confined to the boundaries of its analysis. We critically evaluate the credibility of the extraction paradox and show that it is defused by the presence of the convenience yield. The models involving the option holding cost and 
changing exercise price, both singly and together, are reformulated with the inclusion of the convenience yield, and this analysis brings out some interesting new insights. Although topics outside of his model boundaries, such as suspension, technology and competition, could have been explored, we restrict our attention to his model and its legacy.

\section{Extraction Paradox}

Although Tourinho demonstrates the paradox through a portfolio valuation technique, our approach relies on formulating the model in terms of the risk neutral valuation relationship. The advantage of this approach is that a direct comparison can be made between his model and later work on the same topic.

The Tourinho model makes several important assumptions. The prospective resource owner is assumed to be a price-taker whose output is instantaneously absorbed by the market without any price alteration. The option valuation model requires that the resource owner can borrow and lend at the constant risk-free interest rate and is permitted to short sell the asset. Further, the underlying asset is assumed to be traded continuously in the absence of any transaction costs. Finally, the stochastic price evolution for the underlying asset is treated to be geometric Brownian motion with constant drift and constant volatility in order to facilitate a closed form solution.

In his model, which is formulated in terms of a unit of extracted resource, $\mathrm{S}$ denotes the stochastic resource price and $\mathrm{X}$, the marginal extraction cost acts as the option's exercise price. This cost is interpreted as the sum of the unit cost of mining, refining and transporting and the per unit rental cost of capital equipment.. The resource price behaves according to:

$$
\mathrm{dS}=\mu \mathrm{Sdt}+\sigma \mathrm{Sdz}
$$

where $\mu$ is the required constant return for the extracted asset and $\sigma$ is the volatility. The process for the option to invest $C$ is derived from applying Ito's lemma to (1):

$$
\mathrm{dC}=\left(\frac{\partial \mathrm{C}}{\partial \mathrm{t}}+\frac{1}{2} \sigma^{2} \mathrm{~S}^{2} \frac{\partial^{2} \mathrm{C}}{\partial \mathrm{S}^{2}}\right) \mathrm{dt}+\frac{\partial \mathrm{C}}{\partial \mathrm{S}} \mathrm{dS}
$$


The instantaneous return for a hedged portfolio $\mathrm{V}=\alpha \mathrm{S}+\mathrm{C}$ is:

$$
d V=\left(\frac{\partial C}{\partial t}+\frac{1}{2} \sigma^{2} S^{2} \frac{\partial^{2} C}{\partial S^{2}}\right) d t+\left(\alpha+\frac{\partial C}{\partial S}\right) d S
$$

By setting $\alpha=-\frac{\partial C}{\partial S}$, the portfolio is risk-free and earns the risk-free rate $r$. Since the option is perpetual, $\frac{\partial \mathrm{C}}{\partial \mathrm{t}}=0$ it follows that the fundamental risk neutral valuation relationship is:

$$
\frac{1}{2} \sigma^{2} S^{2} \frac{\partial^{2} C}{\partial S^{2}}+r S \frac{\partial C}{\partial S}-r C=0 .
$$

Following Dixit \& Pindyck (1994), the general solution to this partial differential equation takes the form:

$$
\mathrm{C}=\mathrm{A}_{1} \mathrm{~S}^{\beta_{1}}+\mathrm{A}_{2} \mathrm{~S}^{\beta_{2}}
$$

whose characteristic roots are $\beta_{1}=1, \beta_{2}=-\frac{2 \mathrm{r}}{\sigma^{2}}$. Since the option fall tends to zero as the resource price declines to zero, the coefficient $A_{2}=0$. The value matching condition requires that exercise to occur when the option value $\mathrm{C}$ exactly equals the net benefit from extraction, which is the difference between the resource price $S$ and the unit extraction cost $\mathrm{X}$ :

$$
\mathrm{C}=\mathrm{S}-\mathrm{X}
$$

By imposing the smooth pasting condition, it is straightforward to establish that the optimal price $\hat{\mathrm{S}}$ signaling extraction is:

$$
\hat{\mathrm{S}}=\frac{\beta_{1}}{\beta_{1}-1} X
$$

Since $\beta_{1}=1$, there is no finite price signaling extraction and the paradox is demonstrated.

It is important to recognise that the extraction paradox pervades the entirety of Tourinho's analysis and is the motivation for introducing one of the two alternative inducements that enable a finite exercise time to emerge. However, the form of the risk neutral portfolio is misconstrued since it fails to include the convenience yield from 
owning the asset. If the convenience yield can be expressed as a rate $\lambda$ proportional to $S$, then we adjust (3) to:

$$
\mathrm{dV}=\left(\frac{\partial \mathrm{C}}{\partial \mathrm{t}}+\frac{1}{2} \sigma^{2} \mathrm{~S}^{2} \frac{\partial^{2} \mathrm{C}}{\partial \mathrm{S}^{2}}\right) \mathrm{dt}+\left(\alpha+\frac{\partial \mathrm{C}}{\partial \mathrm{S}}\right) \mathrm{dS}+\alpha \lambda \mathrm{Sdt}
$$

The risk neutral valuation relationship is then amended to:

$$
\frac{1}{2} \sigma^{2} S^{2} \frac{\partial^{2} C}{\partial S^{2}}+(r-\lambda) S \frac{\partial C}{\partial S}-r C=0
$$

so the option value becomes:

$$
C=A_{11} S^{\beta_{11}}+A_{12} S^{\beta_{12}}
$$

where $\beta_{11}, \beta_{12}=\left(\frac{1}{2}-\frac{r-\lambda}{\sigma^{2}}\right) \pm \sqrt{\left(\frac{1}{2}-\frac{r-\lambda}{\sigma^{2}}\right)^{2}+\frac{2 r}{\sigma^{2}}}$ and $A_{12}=0$ to ensure that $C$ does not balloon when $\mathrm{S}$ approaches zero. Including the convenience yield, the optimal resource price prompting exercise is $\frac{\beta_{11}}{\beta_{11}-1} X<\infty$, which is finite since $\beta_{11}>1$. Brennan \& Schwartz (1985) derive a similar form of solution to an enlarged resource extraction model through determining the stochastic process for the futures price.

Including the convenience yield in formulating the risk neutral valuation relationship quashes the extraction paradox and removes the need to introduce incentives that are designed to ensure exercise within a finite time. However, despite the theoretical drawback of his formulated model, the incentives in the form of an option holding cost and a rising exercise price retain their attractiveness in the construction of real option deferral investment models.

\section{Tourinho Model with Holding Costs}

The cost per unit of time of holding the option $\mathrm{H}$ is introduced into the model through the stochastic process for C. Revising (2) to include $\mathrm{H}$ yields:

$$
\mathrm{dC}=\left(\frac{1}{2} \sigma^{2} \mathrm{~S}^{2} \frac{\partial^{2} \mathrm{C}}{\partial \mathrm{S}^{2}}-\mathrm{H}\right) \mathrm{dt}+\frac{\partial \mathrm{C}}{\partial \mathrm{S}} \mathrm{dS}
$$


As before, the return on the constructed hedged portfolio is set equal to the risk-free rate and the risk neutral valuation relationship (4) becomes:

$$
\frac{1}{2} \sigma^{2} S^{2} \frac{\partial^{2} C}{\partial S^{2}}+r S \frac{\partial C}{\partial S}-r C=H .
$$

The general solution to this partial differential equation takes the form:

$$
\mathrm{C}=\mathrm{A}_{1} \mathrm{~S}^{\beta_{1}}+\mathrm{A}_{2} \mathrm{~S}^{\beta_{2}}-\frac{\mathrm{H}}{\mathrm{r}},
$$

whose characteristic roots are $\beta_{1}=1, \beta_{2}=-\frac{2 \mathrm{r}}{\sigma^{2}}$.

The model assumes that a prospective option holder acquires the option at a zero premium but simultaneously incurs an option holding cost per unit of time. The existence of an accumulated holding cost implies that it is not viable for the option holder to maintain the option for all possible resource prices since the net return from eventually extracting the resource will fail to compensate the accumulated holding cost for certain initial resource prices. There is an inferior value $\mathrm{Z}$ of the resource price where the option value is zero and below this level, $\mathrm{S} \leq \mathrm{Z}$ the option if held is allowed to lapse or if not held, the option is unacceptable even at a zero price. Also, the option holder will only exercise the option to extract the resource provided that the resource price attains a superior value $\mathrm{W}$ that is sufficient to compensate for the accumulated holding cost, the extraction cost and future resource price variability. Exercise occurs when the option value at this superior level $\mathrm{C}(\mathrm{Z})$ clears the net benefit $\mathrm{S}-\mathrm{X}$. These two conditions are expressed as:

$$
C(S)=\left\{\begin{array}{l}
0 \text { for } S \leq Z, \\
A_{1} S+A_{2} S^{\beta_{2}}-\frac{H}{r} \text { for } Z<S \leq W, \\
S-X \text { for } S \geq W,
\end{array}\right.
$$

where $\beta_{1}$ is set equal to one. From (14), the two value matching conditions for the inferior and superior price levels are respectively:

$$
C(Z)=A_{1} Z+A_{2} Z^{\beta_{2}}-\frac{H}{r}=0,
$$




$$
C(W)=A_{1} W+A_{2} W^{\beta_{2}}-\frac{H}{r}=W-X .
$$

The smooth pasting conditions associated with (15) and (16) are:

$$
\begin{aligned}
& C^{\prime}(Z)=A_{1}+A_{2} \beta_{2} Z^{\beta_{2}-1}=0, \\
& C^{\prime}(Z)=A_{1}+A_{2} \beta_{2} W^{\beta_{2}-1}=1 .
\end{aligned}
$$

The four equations (15), (16), (17) and (18) enable explicit solutions for the four unknowns:

$$
\begin{gathered}
W=\frac{\beta_{2}}{\beta_{2}-1}\left(X-\frac{H}{r}\right)\left[1-\left(1-\frac{r X}{H}\right)^{-\left(\frac{\beta_{2}-1}{\beta_{2}}\right)}\right], \\
Z=\frac{\beta_{2}}{\beta_{2}-1} \frac{H}{r}\left[1-\left(1-\frac{r X}{H}\right)^{\left(\frac{\beta_{2}-1}{\beta_{2}}\right)}\right], \\
A_{1}=\left[1-\left(1-\frac{r X}{H}\right)^{\left.\left(\frac{\beta_{2}-1}{\beta_{2}}\right)\right]^{-1},}\right. \\
A_{2}=\frac{-1}{\beta_{2}}\left[\frac{\beta_{2}}{\beta_{2}-1} \frac{H}{r}\right]^{1-\beta_{2}}\left[1-\left(1-\frac{r X}{H}\right)^{\left(\frac{\beta_{2}-1}{\beta_{2}}\right)}\right]^{-\beta_{2}} .
\end{gathered}
$$

This model has a distinctive formulation dissimilar to the approach adopted by Dixit \& Pindyck (1994) in their analysis of a project investment opportunity whose cash flow is stochastic. In their model, the exercise price is represented by the investment cost of exercising the opportunity and the project value is determined from recognising that the project can be temporarily suspended at a cost when the underlying net cash flow falls to an inferior critical level but reinstated at a cost when they attain a superior critical level. In contrast, the present formulation bundles the investment cost to exercise the extraction option with the continuous operating cost for extracting the resource. This aggregation of both cost sources enables the model to identify when to make the exercise decision by comparing the extracted resource price with its per unit cost. This entails that the total resource quantity to be extracted is known beforehand and that the entire quantity is 
eventually captured. Bearing this mind, we can enquire of the consequences of the extracted resource price falling below its superior critical level W. Continued extraction remains viable when the resource price $\mathrm{S}$ is less than $\mathrm{W}$ provided that the unit profit $\mathrm{S}-\mathrm{X}$ is positive. If the unit profit becomes negative, the revenue from extraction fails to compensate the investment cost apportioned over the entire resource quantity and the unit operating cost. Since the Tourinho model ignores suspension, it is not possible to predict the consequences of negative unit profit or to say what would happen when the resource price rises to a higher value. The accounting perspective of aggregating the two distinct cost sources suffers the shortcoming of apportioning the investment cost over the entire resource quantity and of not recognising their different timing implications. Any decision to temporarily suspend extraction activities following exercise ought to be governed by the unit operating cost and any costs incurred during suspension, and not involve the sunk investment cost. In the model's defence, it could be argued that extraction continues unabated until the resource is depleted irrespective of concerns of viability and that suspension however temporary is never permitted. However, this requirement makes the model less credible since it entails that management has the discretion when to start the extraction activities but not when to suspend them.

A unique contribution of Tourinho's analysis is the inclusion of the option holding cost. He explains the presence of this cost as the opportunity cost of holding the land locating the resource or as a continuous license fee or tax that is levied during the option's existence. Clearly, the cost of holding the land can be alternatively formulated as a lump sum cost representing the option's premium $\mathrm{C}$ that the prospective extractor pays to the landowner for writing the call. It is straightforward to revise the model equations to this alternative representation. The term $\frac{\mathrm{H}}{\mathrm{r}}$ is replaced by $\mathrm{C}$ in (15) but eliminated from (16) . Clearly, the option's holding cost as a perpetuity and the option's premium do not yield identical solutions and are not direct substitutes so it may be interesting to enquire of the relative merits of these two alternative ways of charging the prospective extractor prior to exercise and to examine the effects of differing combinations of the two. 
Tourinho performs the sensitivity analysis on this solution from the gradients. The sensitivity analysis generates findings in keeping with expectations. The effect of changes of the oil price volatility, risk-free rate and extraction cost are exhibited in Figures (1), (2) and (3). An alternative way of testing the model is to investigate the effect of reducing the holding cost since the model should collapse to the standard investment opportunity studied by Dixit \& Pindyck (1994). However, his model stipulates that an optimal solution exists only when $\mathrm{H}>\mathrm{rX}$ and there is no solution for $\mathrm{H}=0$. The explanation for this failure is the omission of the convenience yield from the valuation relationship.

\section{Revised Model with Holding Costs}

The remedy to the convenience yield omission is to adapt (9) to include the holding cost:

$$
\frac{1}{2} \sigma^{2} S^{2} \frac{\partial^{2} C}{\partial S^{2}}+(r-\lambda) S \frac{\partial C}{\partial S}-r C=H .
$$

Using this risk neutral valuation relationship, we proceed to revise the model equations (15), (16), (17) and (18) and to determine the solution from:

$$
\begin{gathered}
A_{1} Z^{\beta_{1}}+A_{2} Z^{\beta_{2}}-\frac{H}{r}=0, \\
A_{1} W^{\beta_{1}}+A_{2} W^{\beta_{2}}-\frac{H}{r}=W-X, \\
A_{1} \beta_{1} Z^{\beta_{1}-1}+A_{2} \beta_{2} Z^{\beta_{2}-1}=0, \\
A_{1} \beta_{1} W^{\beta_{1}-1}+A_{2} \beta_{2} W^{\beta_{2}-1}=1 .
\end{gathered}
$$

We eliminate $A_{2}$ from (24) and (26) to yield:

$$
\mathrm{A}_{1}=\frac{\beta_{2}}{\beta_{2}-\beta_{1}} \frac{\mathrm{H}}{\mathrm{r}} \frac{1}{\mathrm{Z}^{\beta_{1}}} .
$$

Similarly, from (25) and (27) to yield:

$$
\mathrm{A}_{1}=\frac{\left(1-\frac{1}{\beta_{2}}\right) \mathrm{W}-\mathrm{X}+\frac{\mathrm{H}}{\mathrm{r}}}{\left(1-\frac{\beta_{1}}{\beta_{2}}\right) \mathrm{W}^{\beta_{1}}} .
$$

Eliminating $A_{1}$ from (28) and (29) yields:

$$
\mathrm{Z}=\theta \mathrm{W},
$$


where

$$
\theta=\left[\frac{\mathrm{H}}{\mathrm{r}}\right]^{\frac{1}{\beta_{1}}}\left[\mathrm{~W}\left(1-\frac{1}{\beta_{2}}\right)+\left(\frac{\mathrm{H}}{\mathrm{r}}-\mathrm{X}\right)\right]^{-\frac{1}{\beta_{1}}} .
$$

Eliminating $\mathrm{A}_{2}$ from (26) and (27) yields:

$$
\mathrm{A}_{1}=\frac{\mathrm{WZ}^{\beta_{2}}}{\beta_{1}\left(\mathrm{~W}^{\beta_{1}} \mathrm{Z}^{\beta_{2}}-\mathrm{W}^{\beta_{2}} \mathrm{Z}^{\beta_{1}}\right)} .
$$

Eliminating $A_{1}$ from (28) and (32), and using (30) yields:

$$
\mathrm{W}=\frac{-\beta_{1} \beta_{2}}{\beta_{1}-\beta_{2}} \frac{\mathrm{H}}{\mathrm{r}}\left[\theta^{-\beta_{1}}-\theta^{-\beta_{2}}\right] .
$$

Together (31) and (33) give the implicit solution for W, which has to be solved numerically. $Z$ is evaluated from (30), $A_{1}$ from (28) and $A_{2}$ from (26).

The sensitivity of the optimal solution to changes in the convenience yield and the holding cost can be investigated graphically. Table 1 specifies the base case values for the various parameters; the calculated values of $\beta_{1}$ and $\beta_{2}$ are 1.193 and -4.193 respectively. Figure (4) exhibits the effect of changes in the convenience yield on the optimal resource price values for acquiring and exercising the option. It reveals that the revised and Tourinho model produce identical results for a zero convenience yield. Increases in the convenience yield produce a rise in the optimal resource for acquiring the option and a fall in the optimal resource for exercising it. Since the convenience yield provides a benefit from owning the resource, the option owner is motivated to extract the resource earlier for greater convenience yield values. Similarly, because of the disincentive in holding the option relative to the resource due to the convenience yield, the prospective extractor will acquire the option later for greater convenience yield values.

Table 1: Base Case Values

$\begin{array}{lr}\text { Extraction cost X } & 20 \\ \text { Volatility } \sigma & 20 \% \\ \text { Risk-free rate } \mathrm{r} & 10 \%\end{array}$




\section{Holding cost $\mathrm{H} \quad 3.5$ \\ Convenience yield $\lambda \quad 2.0 \%$}

Figure (5) exhibits the relationship between the optimal solution and the holding cost. In contrast to the Tourinho model that fails to provide a feasible solution for a certain range of holding costs, the revised formulation collapses to the standard real options investment

opportunity model for which $\mathrm{Z}=0$ and $\mathrm{W}=\frac{\beta_{1}}{\beta_{1}-1} \mathrm{X}=123.85$. Increasing the holding cost initially produces a significant fall in $\mathrm{W}$ and a significant rise in $\mathrm{Z}$ until the two curves meet asymptotically at the exercise price $\mathrm{X}$ for an infinitely large holding cost. When the holding cost is relatively large, there exists little economic justification for holding the option and the prospective extractor will acquire and exercise the option simultaneously. Variations in the holding cost produce the standard real options result when $\mathrm{H}=0$ and the Marshallian perfect competition result when $\mathrm{H}=\infty$. It is interesting to observe that the relative change in the holding cost has a significantly greater relative impact on the optimal solution than a similar change in the convenience yield. This implies that greater care needs to be exerted in evaluating the holding cost relative to the convenience yield because of the effect of their measurement errors on the optimal values. It also suggests that Tourinho may have, perhaps unwittingly, recognised the greater importance of the holding cost. Subsequent work on real options theory has not awarded sufficient attention to the option holding cost and the manner by which it influences the optimal investment policy varying between the extremes of the standard real options result for $\mathrm{H}=0$ and the Marshallian result when $\mathrm{H}=\infty$. In this way, the effect of the holding cost on the optimal solution is similar to competition and it represents one of those factors explaining the possible limitations of the standard real options model.

\section{Tourinho Model with Storage Costs}

The holding cost model is enlarged by introducing a storage cost of the extracted resource into the analysis. The storage cost is specified as $\mathrm{K}$ per unit of time. The analysis proceeds as before by deriving the risk neutral valuation relationship by identifying the 
return on the hedged portfolio as risk-free. His resulting partial differential equation takes the form:

$$
\frac{1}{2} \sigma^{2} S^{2} \frac{\partial^{2} \mathrm{C}}{\partial \mathrm{S}^{2}}+(\mathrm{rS}+\mathrm{K}) \frac{\partial \mathrm{C}}{\partial \mathrm{S}}-\mathrm{rC}-\mathrm{H}=0 .
$$

The boundary conditions are the same as before. Although the solution to (34) takes the form of the confluent hyper-geometric series, Tourinho elects to adopt a finite difference equation approach and determines a numerical solution, which is observed to be little different from the case having no storage cost.

There is little economic justification for including the storage cost in the formulation except that the resource extractor would normally hold a final goods inventory before selling. When holding an oil inventory is a normal business practice, its costs could have been absorbed in the unit extraction cost. An alternative representation is to hypothesise that the resource price stimulates the need for storage so the extractor is accumulating oil reserves when its price is below viability with the intention of off-loading it when a more favourable price emerges. In this representation, suspending the resource extraction is avoided when the oil price dips below a certain critical level by investing in storage facilities and then stockpiling the resource until a favourable price is observed.

It is interesting to observe that by reframing the storage cost as proportional to the resource price $\mathrm{K}=\lambda \mathrm{S}$, then (34) simplifies to the form involving a convenience yield (9), except for the negative sign.

\section{Tourinho Model with Rising Extraction Cost}

The extraction paradox can also be resolved by motivating the prospective extractor to exercise the option within a finite time by forcing the exercise price, which is the unit extraction cost, to rise exponentially over time. Imposing a rising extraction cost is considered to induce the option holder to prefer an early exercise as it acts as a deterrence against tardiness. The unit extraction is specified by:

$$
\mathrm{dX}=\mathrm{gXdt} \text {. }
$$


Tourinho then claims that the option value has to satisfy (4) and the exercise boundary condition is:

$$
\mathrm{C}=\operatorname{Max}\{0, \mathrm{~S}-\mathrm{X}(\mathrm{t})\} .
$$

Following Merton (1973), the formulation is rescaled in units of the exercise price by considering $\mathrm{s}=\frac{\mathrm{S}}{\mathrm{X}}$ and $\mathrm{D}=\frac{\mathrm{C}}{\mathrm{X}}$. Then (4) reduces to:

$$
\frac{1}{2} \sigma^{2} s^{2} \frac{\partial^{2} D}{\partial s^{2}}+(r-g) s \frac{\partial D}{\partial s}-(r-g) D=0,
$$

whose solution is:

$$
\mathrm{D}=\mathrm{A}_{31} \mathrm{~s}^{\beta_{31}}+\mathrm{A}_{32} \mathrm{~s}^{\beta_{32}}
$$

where:

$$
\begin{aligned}
& \beta_{31}=1, \\
& \beta_{32}=\frac{2(g-r)}{\sigma^{2}} .
\end{aligned}
$$

The value matching condition at $\mathrm{s}=\mathrm{w}$, the point of exercise:

$$
\mathrm{A}_{31} \mathrm{w}^{\beta_{31}}+\mathrm{A}_{32} \mathrm{w}^{\beta_{32}}=\mathrm{w}-1 .
$$

Tourinho argues that since the high impact condition at exercise demands that:

$$
\frac{\partial^{2} \mathrm{D}}{\partial \mathrm{s}^{2}}=\mathrm{A}_{31} \beta_{31}\left(\beta_{31}-1\right) \mathrm{s}^{\beta_{31}-2}+\mathrm{A}_{32} \beta_{32}\left(\beta_{32}-1\right) \mathrm{s}^{\beta_{32}-2}>0,
$$

this condition cannot be satisfied for any value of $A_{31}$ so it is set equal to zero, but is satisfied provided that $\beta_{32}>1$ so $g>r+\frac{1}{2} \sigma^{2}$. By interpreting $r+\frac{1}{2} \sigma^{2}$ as the risk adjusted rate for the resource price, the growth rate of the extraction cost has to exceed for risk adjusted rate for exercise to occur within a finite time. The argument used to derive this solution is somewhat convoluted and contrived, but it can be avoided by reformulating the model.

\section{Revised Model with Increasing Extraction Cost}

The solution to the model with rising extraction cost has to rely on the ploy that $A_{31}=0$ and $\beta_{32}>1$ because of the omission of the convenience yield. When a positive convenience yield is incorporated in the analysis, the Tourinho argument required to derive the solution becomes redundant. The resource price follows a geometric Brownian 
motion process (1). Although the extraction cost process (35) is not stochastic, for completeness it is treated to also follow a geometric Brownian process:

$$
\mathrm{dX}=\mathrm{gXdt}+\sigma_{\mathrm{X}} \mathrm{Xdz_{X }}
$$

except that it is not correlated with any market traded instrument. The option to invest is denoted by $\mathrm{C}=\mathrm{C}(\mathrm{S}, \mathrm{X})$ since its value depends on the values of both the resource price and the extraction cost. Using Trigeorgis (1996), the change in option value is given by:

$$
\mathrm{dC}=\left(\frac{1}{2} \sigma^{2} \mathrm{~S}^{2} \frac{\partial^{2} \mathrm{C}}{\partial \mathrm{S}^{2}}+\frac{1}{2} \sigma_{X}^{2} \mathrm{X}^{2} \frac{\partial^{2} \mathrm{C}}{\partial \mathrm{X}^{2}}\right) \mathrm{dt}+\frac{\partial \mathrm{C}}{\partial \mathrm{S}} \mathrm{dS}+\frac{\partial \mathrm{C}}{\partial \mathrm{X}} \mathrm{dX}
$$

Consider a portfolio $\mathrm{V}=\mathrm{C}+\alpha \mathrm{S}$, then the change in portfolio value is:

$$
d V=\left(\frac{1}{2} \sigma^{2} S^{2} \frac{\partial^{2} C}{\partial S^{2}}+\frac{1}{2} \sigma_{X}^{2} X^{2} \frac{\partial^{2} C}{\partial X^{2}}+g X \frac{\partial C}{\partial X}\right) d t+\left(\alpha+\frac{\partial C}{\partial S}\right) d S+\alpha \lambda S d t
$$

The portfolio $\mathrm{V}$ is fully hedged when $\alpha=-\frac{\partial \mathrm{C}}{\partial \mathrm{S}}$ and earns a risk-free rate, so:

$$
\frac{1}{2} \sigma^{2} S^{2} \frac{\partial^{2} C}{\partial S^{2}}+\frac{1}{2} \sigma_{X}^{2} X^{2} \frac{\partial^{2} C}{\partial X^{2}}+g X \frac{\partial C}{\partial X}+(r-\lambda) \frac{\partial C}{\partial S}-r C=0
$$

McDonald \& Siegel (1986) determine the value of the deferral option to invest involving two stochastic variables by deploying homogeneity of degree one and using the ratio transformation $\mathrm{s}=\frac{\mathrm{S}}{\mathrm{X}}$ to reduce the dimensionality of the partial differential equation to one. We derive their solution through an alternative route that is deployed later to solve a more complicated case. The risk neutral valuation relationship (43) has the generic solution:

$$
\mathrm{C}=\mathrm{A}_{4} \mathrm{~S}^{\beta_{4}} \mathrm{X}^{\gamma_{4}}
$$

It is straightforward to demonstrate that (44) satisfies the partial differential equation (43) when:

$$
\mathrm{Q}\left(\beta_{4}, \gamma_{4}\right)=\frac{1}{2} \sigma^{2} \beta_{4}\left(\beta_{4}-1\right)+\frac{1}{2} \sigma_{\mathrm{X}}^{2} \gamma_{4}\left(\gamma_{4}-1\right)+\mathrm{g} \gamma_{4}+(\mathrm{r}-\lambda) \beta_{4}-\mathrm{r}=0
$$

which defines the characteristic roots for the solution. Since Q represents an elliptical function defined over the four quadrants, it becomes important to reduce the search area for $\beta_{4}$ and $\gamma_{4}$. 
We alter the previous notation by denoting the resource and exercise prices when the option is exercised by $\hat{\mathrm{S}}$ and $\hat{\mathrm{X}}$ respectively. The option is exercised at $\mathrm{S}=\hat{\mathrm{S}}$ and $\mathrm{X}=\hat{\mathrm{X}}$ when the option value $C(\hat{S}, \hat{X})$ is equal to its net return $\hat{S}-\hat{X}$ :

$$
\mathrm{A}_{4} \hat{\mathrm{S}}^{\beta_{4}} \hat{\mathrm{X}}^{\gamma_{4}}=\hat{\mathrm{S}}-\hat{\mathrm{X}} \text {. }
$$

It is straightforward to establish that the value matching condition (46) satisfies the requirement for homogeneity of degree one, Adkins \& Paxson (2006), so $\beta_{4}+\gamma_{4}=1$ implying that (45) simplifies to:

$$
\beta_{4}\left(\beta_{4}-1\right)\left(\frac{1}{2} \sigma^{2}+\frac{1}{2} \sigma_{X}^{2}\right)+(r-\lambda-g) \beta_{4}-(r-g)=0
$$

The characteristic roots of (47) are:

$$
\begin{aligned}
& \beta_{41}=\left(\frac{1}{2}-\frac{\mathrm{r}-\lambda-\mathrm{g}}{\sigma^{2}+\sigma_{\mathrm{X}}^{2}}\right)+\sqrt{\left(\frac{1}{2}-\frac{\mathrm{r}-\lambda-\mathrm{g}}{\sigma^{2}+\sigma_{\mathrm{X}}^{2}}\right)^{2}+\frac{2(\mathrm{r}-\mathrm{g})}{\sigma^{2}+\sigma_{\mathrm{X}}^{2}}}>1, \\
& \beta_{42}=\left(\frac{1}{2}-\frac{\mathrm{r}-\lambda-\mathrm{g}}{\sigma^{2}+\sigma_{\mathrm{X}}^{2}}\right)-\sqrt{\left(\frac{1}{2}-\frac{\mathrm{r}-\lambda-\mathrm{g}}{\sigma^{2}+\sigma_{\mathrm{X}}^{2}}\right)^{2}+\frac{2(\mathrm{r}-\mathrm{g})}{\sigma^{2}+\sigma_{\mathrm{X}}^{2}}}<0, \\
& \gamma_{41}=1-\beta_{41}<0, \\
& \gamma_{42}=1-\beta_{42}>1 .
\end{aligned}
$$

The option valuation relationship (44) then takes the specific form:

$$
\mathrm{C}(\mathrm{S}, \mathrm{X})=\mathrm{A}_{41} \mathrm{~S}^{\beta_{41}} \mathrm{X}^{\gamma_{41}}+\mathrm{A}_{42} \mathrm{~S}^{\beta_{42}} \mathrm{X}^{\gamma_{42}}
$$

Since the option value is zero for $\mathrm{S}=0$, the coefficient $\mathrm{A}_{42}=0$ and the value matching condition (46) becomes:

$$
\mathrm{A}_{41} \hat{\mathrm{S}}^{\mathrm{S}_{41}} \hat{\mathrm{X}}^{\gamma_{41}}=\hat{\mathrm{S}}-\hat{\mathrm{X}} \text {. }
$$

The associated smooth pasting conditions for $\mathrm{S}$ and $\mathrm{X}$ are respectively:

$$
\begin{gathered}
\mathrm{A}_{41} \beta_{41} \hat{\mathrm{S}}^{\beta_{41}-1} \hat{\mathrm{X}}^{\gamma_{41}}=1, \\
\mathrm{~A}_{41} \gamma_{41} \hat{\mathrm{S}}^{\beta_{41}} \hat{\mathrm{X}}^{\gamma_{41}-1}=-1 .
\end{gathered}
$$

Since $\beta_{41}+\gamma_{41}=1$, (51) and (52) are equivalent, which implies that only two independent equations (50) and (51) are available to solve the three unknowns $\mathrm{A}_{41}, \hat{\mathrm{S}}$ and $\hat{\mathrm{X}}$. However, it is feasible to derive unique solutions for $\mathrm{A}_{41}$ and $\hat{\mathrm{s}}=\frac{\hat{\mathrm{S}}}{\hat{\mathrm{X}}}$ : 


$$
\begin{aligned}
\mathrm{A}_{41} & =\frac{1}{\beta_{41}}\left(\frac{\beta_{41}}{\beta_{41}-1}\right)^{1-\beta_{41}}, \\
\hat{\mathrm{s}} & =\frac{\beta_{41}}{\beta_{41}-1} .
\end{aligned}
$$

Incorporating the holding cost into the formulation introduces a complication in the analytical derivation because the condition underpinning homogeneity of degree one is not met. The risk neutral valuation relationship (43) is modified to include the option cost:

$$
\frac{1}{2} \sigma^{2} S^{2} \frac{\partial^{2} C}{\partial S^{2}}+\frac{1}{2} \sigma_{X}^{2} X^{2} \frac{\partial^{2} C}{\partial X^{2}}+g X \frac{\partial C}{\partial X}+(r-\lambda) \frac{\partial C}{\partial S}-r C=H
$$

The generic solution to this partial differential equation is:

$$
\mathrm{C}=\mathrm{A}_{5} \mathrm{~S}^{\beta_{5}} \mathrm{X}^{\gamma_{5}}-\frac{\mathrm{H}}{\mathrm{r}}
$$

It is straightforward to establish that (54) satisfies (53) when (45) holds. We revise the notation to accommodate that the acquisition and exercise option occur at distinct points by denoting the resource prices when the option is acquired and exercised by $\hat{\overline{\mathrm{S}}}$ and $\underline{\hat{\mathrm{S}}}$ respectively, and the corresponding values for the exercise price by $\hat{\overline{\mathrm{X}}}$ and $\underline{\hat{\mathrm{X}}}$. The option is exercised at $S=\hat{\bar{S}}$ and $X=\hat{\bar{X}}$ when the option value $C(\hat{\bar{S}}, \hat{\bar{X}})$ is equal to its net return $\hat{\overline{\mathrm{S}}}-\hat{\overline{\mathrm{X}}}$ :

$$
\mathrm{A}_{5} \hat{\overline{\mathrm{S}}}^{\beta_{5}} \hat{\overline{\mathrm{X}}}^{\gamma_{5}}-\frac{\mathrm{H}}{\mathrm{r}}=\hat{\overline{\mathrm{S}}}-\hat{\overline{\mathrm{X}}}
$$

Because of the inclusion of the holding cost term, the value matching condition (55) fails to satisfy the requirement for homogeneity of degree one, Adkins \& Paxson (2006), $\beta_{5}+\gamma_{5} \neq 1$ and the simplification used above becomes untenable.

In line with the Tourinho model, we surmise that the specific solution to (53) takes the form:

$$
\mathrm{C}=\mathrm{A}_{51} \mathrm{~S}^{\beta_{51}} \mathrm{X}^{\gamma_{51}}+\mathrm{A}_{52} \mathrm{~S}^{\beta_{52}} \mathrm{X}^{\gamma_{52}}-\frac{\mathrm{H}}{\mathrm{r}}
$$

When the option is exercised, the value matching condition is: 


$$
\mathrm{A}_{51} \hat{\overline{\mathrm{S}}}^{\beta_{51}} \hat{\overline{\mathrm{X}}}^{\gamma_{51}}+\mathrm{A}_{52} \hat{\overline{\mathrm{S}}}^{\beta_{52}} \hat{\overline{\mathrm{X}}}^{\gamma_{52}}-\frac{\mathrm{H}}{\mathrm{r}}=\hat{\overline{\mathrm{S}}}-\hat{\overline{\mathrm{X}}}
$$

The associated two smooth pasting conditions respectively for $\mathrm{S}$ and $\mathrm{X}$ are:

$$
\begin{aligned}
& \mathrm{A}_{51} \beta_{51} \hat{\overline{\mathrm{S}}}^{\beta_{51}-1} \hat{\overline{\mathrm{X}}}^{\gamma_{51}}+\mathrm{A}_{52} \beta_{52} \hat{\overline{\mathrm{S}}}^{\beta_{52}-1} \hat{\overline{\mathrm{X}}}^{\gamma_{52}}=1, \\
& \mathrm{~A}_{51} \gamma_{51} \hat{\overline{\mathrm{S}}}^{\beta_{51}} \hat{\overline{\mathrm{X}}}^{\gamma_{51}-1}+\mathrm{A}_{52} \gamma_{52} \hat{\overline{\mathrm{S}}}^{\beta_{52}} \hat{\overline{\mathrm{X}}}^{\gamma_{52}-1}=-1 .
\end{aligned}
$$

When the option is acquired, the value matching condition is:

$$
\mathrm{A}_{51} \underline{\hat{S}}^{\beta_{51}} \underline{\hat{X}}^{\gamma_{51}}+\mathrm{A}_{52} \underline{\hat{\mathrm{S}}}^{\beta_{52}} \underline{\hat{X}}^{\gamma_{52}}-\frac{\mathrm{H}}{\mathrm{r}}=0 .
$$

The associated two smooth pasting conditions respectively for $\mathrm{S}$ and $\mathrm{X}$ are:

$$
\begin{aligned}
& \mathrm{A}_{51} \beta_{51} \underline{\hat{\mathrm{S}}}^{\beta_{51}-1} \underline{\hat{X}}^{\gamma_{51}}+\mathrm{A}_{52} \beta_{52} \underline{\hat{\mathrm{S}}}^{\beta_{52}-1} \underline{\hat{X}}^{\gamma_{52}}=0, \\
& \mathrm{~A}_{51} \gamma_{51} \underline{\hat{\mathrm{S}}}^{\beta_{51}} \underline{\hat{X}}^{\gamma_{51}-1}+\mathrm{A}_{52} \gamma_{52} \underline{\hat{\mathrm{S}}}^{\beta_{52}} \underline{\hat{\mathrm{X}}}^{\gamma_{52}-1}=0
\end{aligned}
$$

The formulation has ten unknown quantities: $\mathrm{A}_{51}, \mathrm{~A}_{52}, \hat{\overline{\mathrm{S}}}, \hat{\overline{\mathrm{X}}}, \underline{\hat{\mathrm{S}}}, \underline{\hat{\mathrm{X}}}, \beta_{51}, \gamma_{51}, \beta_{52}, \gamma_{52}$. In contrast, there are eight independent equations: two value matching conditions and for each two smooth pasting conditions, a two $Q$ functions $\left(\mathrm{Q}\left(\beta_{51}, \gamma_{51}\right)=0, \mathrm{Q}\left(\beta_{52}, \gamma_{52}\right)=0\right)$. There is no unique solution as in the previous case without holding costs.

In the following analysis, we surmise that $\beta_{51}>0, \gamma_{51}<0$ and $\beta_{52}<0, \gamma_{52}>0$ to ensure that the sign of the smooth pasting conditions are sensible (the converse could have been assumed but the same findings result). Since the $\mathrm{Q}$ function is elliptical, a defined curve derived from the value matching and smooth pasting conditions has to pass through this ellipse at the two distinct points, $\beta_{51}>0, \gamma_{51}<0$ and $\beta_{52}<0, \gamma_{52}>0$. Now, it follows from (61) and (62) that:

$$
\frac{\beta_{51}}{\gamma_{51}}=\frac{\beta_{52}}{\gamma_{52}}<0 .
$$

Combining (60) with (61) and (62) yields respectively:

$$
\begin{aligned}
& \mathrm{A}_{51}=\frac{-\beta_{52}}{\left(\beta_{51}-\beta_{52}\right)} \frac{\mathrm{H} / \mathrm{r}}{\hat{\mathrm{S}}^{\beta^{51}} \underline{\hat{X}}^{\gamma_{51}}}>0, \\
& \mathrm{~A}_{52}=\frac{\beta_{51}}{\left(\beta_{51}-\beta_{52}\right)} \frac{\mathrm{H} / \mathrm{r}}{\hat{\mathrm{S}}^{\beta_{52}} \underline{\hat{X}}^{\gamma_{52}}}>0 .
\end{aligned}
$$


To simplify the analysis, we define:

$$
\mathrm{L}_{1}=\frac{\hat{\overline{\mathrm{S}}}^{\beta_{51}} \hat{\overline{\mathrm{X}}}^{\gamma_{51}}}{\underline{\hat{\mathrm{S}}}^{\beta_{51}} \underline{\hat{\mathrm{X}}}^{\gamma_{51}}}>0, \mathrm{~L}_{2}=\frac{\hat{\overline{\mathrm{S}}}^{\beta_{52}} \hat{\overline{\mathrm{X}}}^{\gamma_{52}}}{\underline{\hat{\mathrm{S}}}^{\beta_{52}} \underline{\hat{X}}^{\gamma_{52}}}>0, \mathrm{~L}_{1}>\mathrm{L}_{2} .
$$

Substituting the values for $A_{51}$ and $A_{52}$ in (58), (59) and (57) yields respectively:

$$
\begin{gathered}
\frac{-\beta_{51} \beta_{52}}{\left(\beta_{51}-\beta_{52}\right)} \frac{\mathrm{H}}{\mathrm{r}}\left(\mathrm{L}_{1}-\mathrm{L}_{2}\right)=\hat{\overline{\mathrm{S}}}>0, \\
\frac{-\beta_{51} \gamma_{52}}{\left(\beta_{51}-\beta_{52}\right)} \frac{\mathrm{H}}{\mathrm{r}}\left(\mathrm{L}_{1}-\mathrm{L}_{2}\right)=-\hat{\overline{\mathrm{X}}}<0, \\
\frac{-\beta_{52} \mathrm{~L}_{1}}{\left(\beta_{51}-\beta_{52}\right)} \frac{\mathrm{H}}{\mathrm{r}}+\frac{\beta_{51} \mathrm{~L}_{1}}{\left(\beta_{51}-\beta_{52}\right)} \frac{\mathrm{H}}{\mathrm{r}}-\frac{\mathrm{H}}{\mathrm{r}}=\hat{\overline{\mathrm{S}}}-\hat{\overline{\mathrm{X}}}>0 .
\end{gathered}
$$

Incorporating (63) in the ratio of (66) and (67) yields:

$$
\hat{\overline{\mathrm{S}}}=-\frac{\beta_{51}}{\gamma_{51}} \hat{\overline{\mathrm{X}}}=-\frac{\beta_{52}}{\gamma_{52}} \hat{\overline{\mathrm{X}}}
$$

When $\mathrm{H}=0$, the formulation reduces to the case of homogeneity of degree one with $\beta_{51}+\gamma_{51}=1$ and (69) simplifies to:

$$
\hat{\overline{\mathrm{S}}}=\frac{\beta_{51}}{\beta_{51}-1} \hat{\overline{\mathrm{X}}}
$$

This is the standard result for the deferral option to invest and therefore the model with holding costs supplies a similar form solution. Substituting (66) and (67) in (68) yields:

$$
-\beta_{52} \mathrm{~L}_{1}\left(1-\beta_{51}-\gamma_{51}\right)+\beta_{51} \mathrm{~L}_{1}\left(1-\beta_{52}-\gamma_{52}\right)=\beta_{51}-\beta_{52}>0
$$

which implies that $1-\beta_{51}-\gamma_{51}>0$ so $\beta_{51}-1<-\gamma_{51}$ and $\frac{\beta_{51}}{\beta_{51}-1}>-\frac{\beta_{51}}{\gamma_{51}}$. The introduction of a holding cost in the general model representing the option to defer an investment with a stochastic asset price and stochastic exercise price produces a fall in the mark-up factor and a reduction in the time before investment ceteris paribus. The holding cost plays a significant role in the model solution and when it is relevant, its omission will consequently lead to erroneous results.

\section{Conclusion}

Tourinho applied contingent claims analysis to investigate the investment opportunity for extracting oil from shale and developed one of the earliest expositions of real options 
analysis that used the comparison between options on financial and physical assets to value the opportunity. Pervading his entire analysis is the extraction paradox that the resource will never be extracted in the absence of suitable inducements. However, the extraction paradox is not corroborated by evidence since resource extractors are observed to accept investment opportunities and start operations within a finite time limit, so Tourinho claims that inducements such as an option holding cost and a rising exercise price have to be introduced into the formulation in order to obtain a realistic solution. He then proceeds to examine the significance of an option holding cost and a rising exercise price and demonstrates that both these factors dispel the paradox and that the model in their presence produces a feasible solution within a finite period of time.

The Tourinho analysis is one of the earliest uses of real options applying the synergy between financial and real options, but his legacy is not significant. A quick guide to his impact is found from the number of citations according to Google Scholar:

$\begin{array}{lr}\text { Work } & \text { Number of Citations } \\ \text { Tourinho (1979) } & 26 \\ \text { Brennan \& Schwartz (1985) } & 654 \\ \text { McDonald \& Siegel (1986) } & 902\end{array}$

Although these estimates are not accurate, they are indicative. Tourinho should be perceived as one of the earliest contributors to real options analysis who demonstrated how the analysis of financial options theory, particularly the American perpetual call, can be applied to physical assets in a meaningful way. But the legacy is not extensive. It is stunted owing to the absence of the convenience yield in the formulation, which led to the existence of the extraction paradox and consequently motivated the ploy used in the derivation of the rising exercise price model to reach an acceptable solution.

An alternative history would have evolved if Tourinho had introduced the convenience yield into the formulation. It is probable that his analysis would have unearthed the incentivising effect of the option holding cost on an early exercise and established the exercise condition to vary between the Marshallian value of one and the standard real options value in excess of one. Current theoretical thinking on investment opportunities 
under uncertainty tends to be aligned with the real options conceptualization and judge these opportunities on their capacity to achieve a mark-up value greater than one. The insight that the option holding cost moderates the required mark-up value between the Marshallian one and the real options value may have radically changed our conceptions of the appropriate mark-up value. 
Figure 1: Effect of Volatility on the Prices to Acquire and Exercise the Option

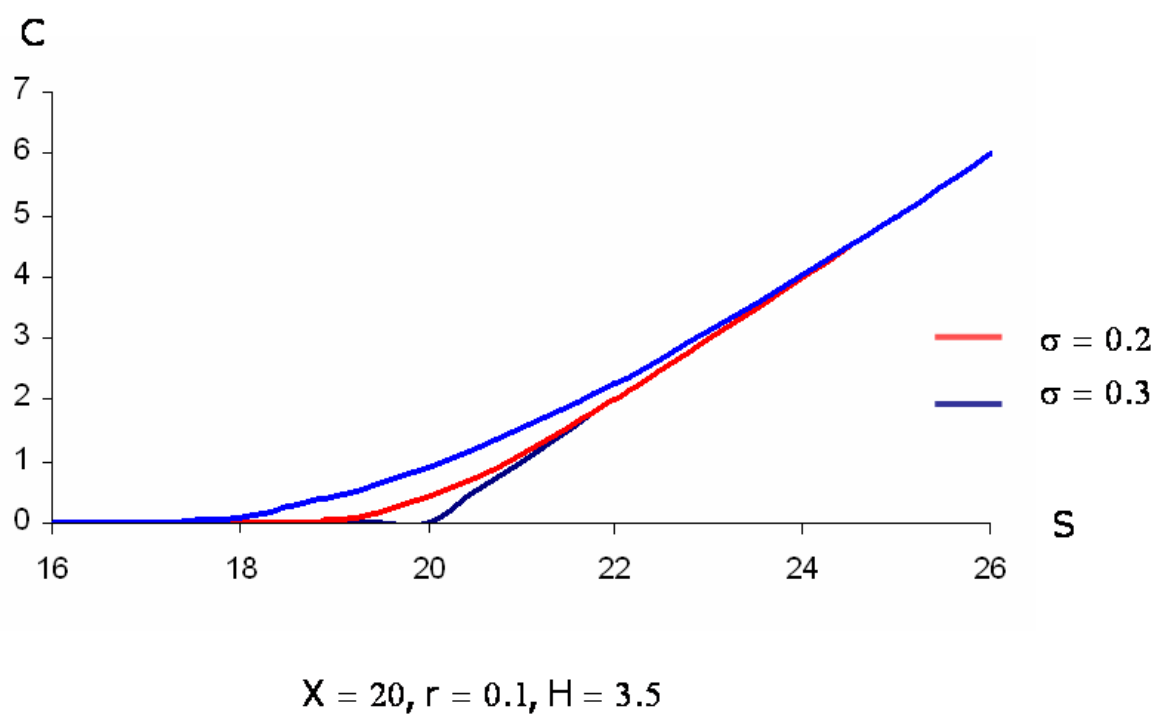


Figure 2: Effect of Risk-free Rate on the Prices to Acquire and Exercise the Option

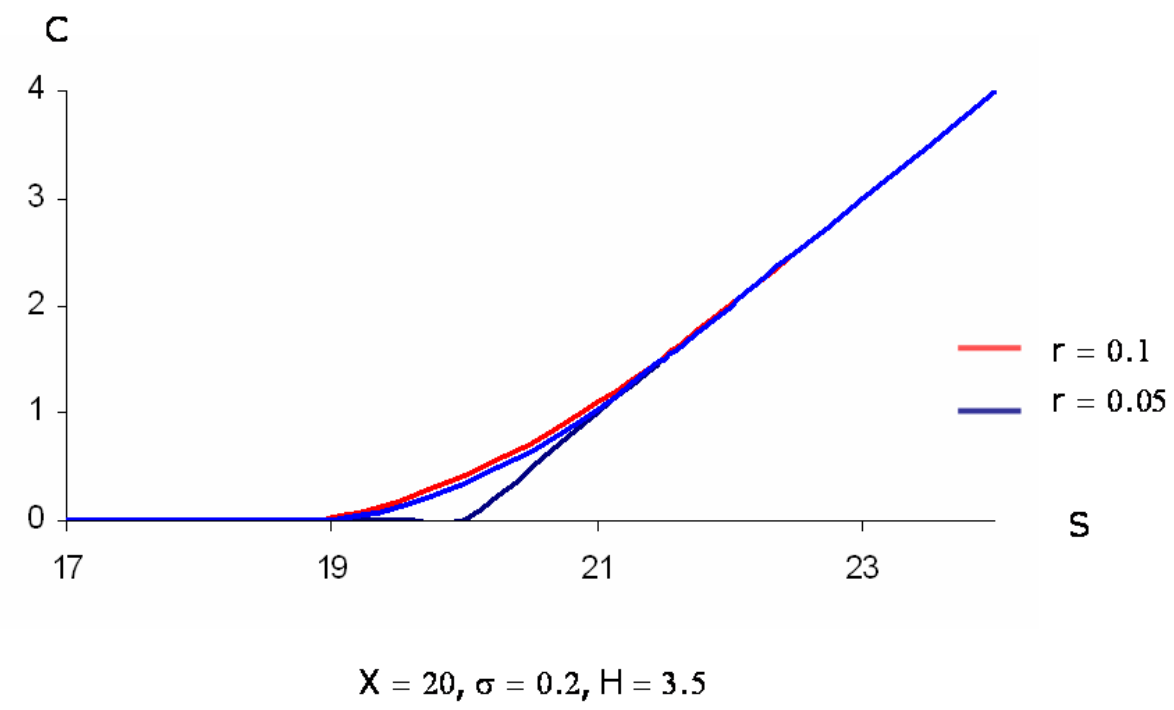


Figure 3: Effect of Exercise Price on the Prices to Acquire and Exercise the Option

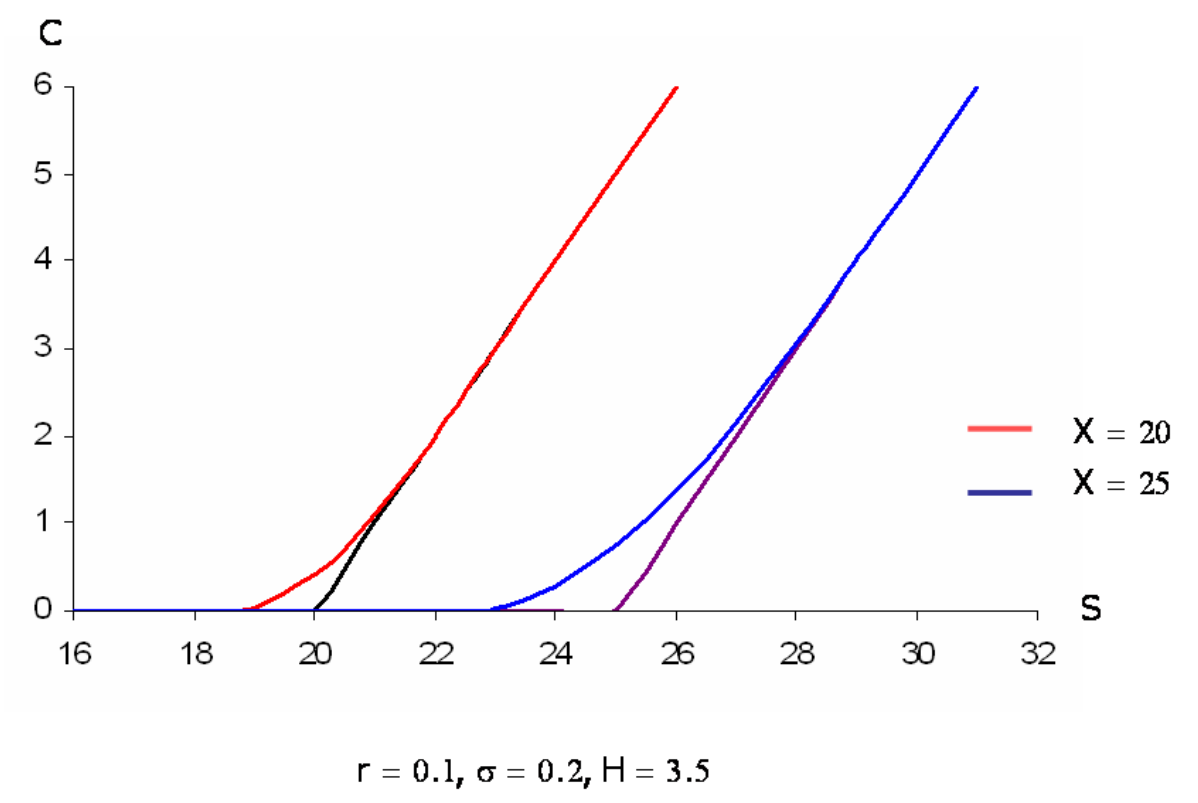


Figure 4: Effect of Convenience Yield on Optimal Solution for Revised Model with Holding Costs

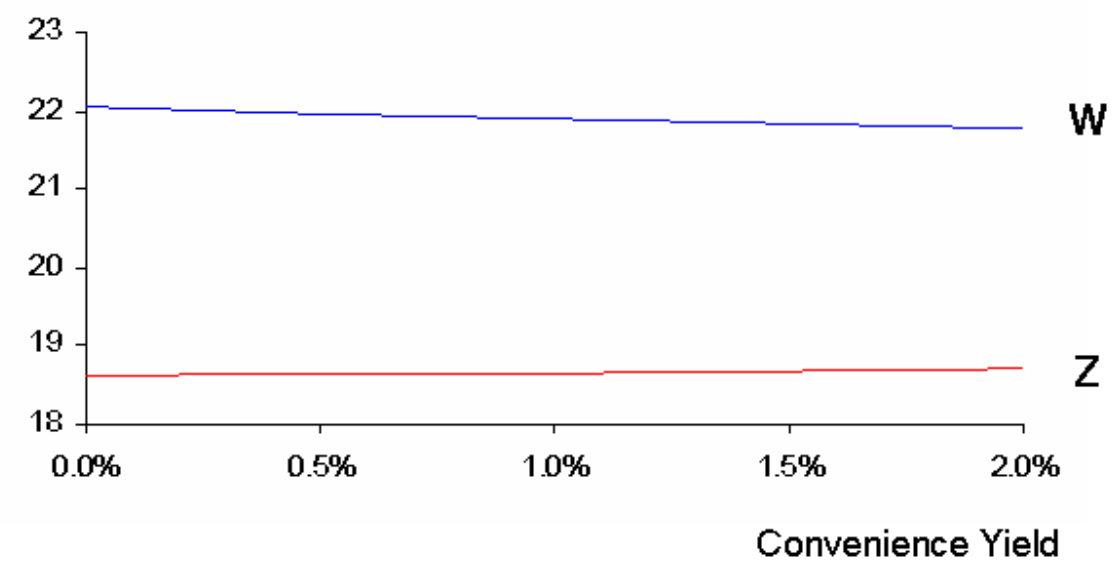

Figure 5: Effect of Holding Cost on Optimal Solution for Revised Model with Holding Costs

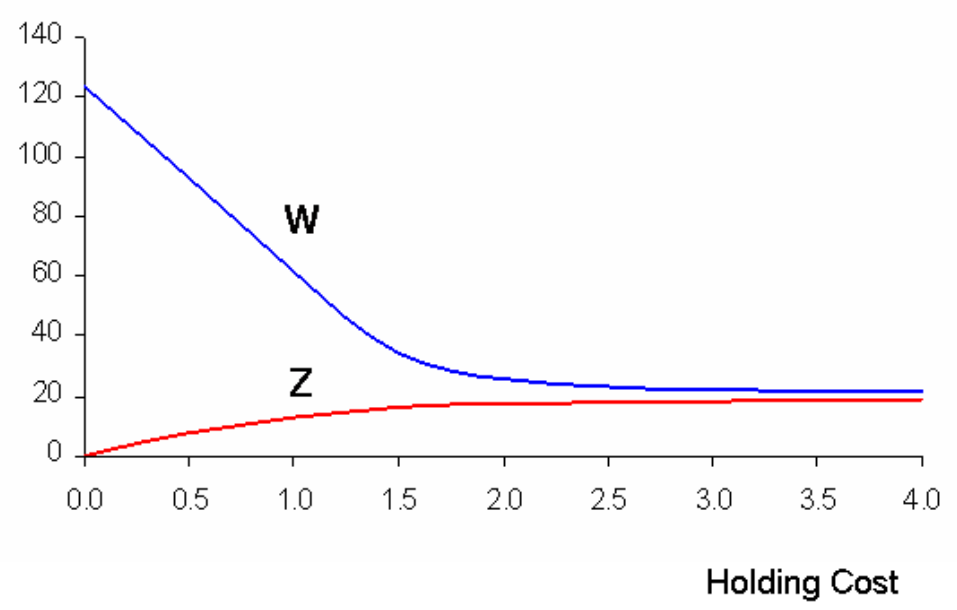




\section{References}

Adkins, R., \& Paxson, D. (2006). Optionality in asset renewals, Real Options Conference. New York.

Brennan, M. J., \& Schwartz, E. S. (1985). Evaluating natural resource investments. Journal of Business, 58(2), 135-157.

Dixit, A. K., \& Pindyck, R. S. (1994). Investment under Uncertainty. Princeton (N.J.): Princeton University Press.

McDonald, R. L., \& Siegel, D. R. (1986). The value of waiting to invest. The Quarterly Journal of Economics, 101(4), 707-728.

Merton, R. C. (1973). Theory of Rational Option Pricing. The Bell Journal of Economics and Management Science, 4(1), 141-183.

Myers, S. C., \& Turnball, S. M. (1976). Capital budgeting and the capital asset pricing model: Good news and bad news. Journal of Finance, 32(2), 321-333.

Tourinho, O. A. F. (1979). The valuation of reserves of natural resources: an option pricing approach: University of California, Berkeley.

Trigeorgis, L. (1996). Real Options: Managerial Flexibility and Strategy in Resource Allocation. Cambridge (Mass.): MIT Press. 